\title{
Physiological and molecular characterizations of the interactions in two cellulose-to-methane cocultures
}

\author{
Hongyuan Lu, Siu-Kin Ng, Yangyang Jia, Mingwei Cai and Patrick K. H. Lee
}

\begin{abstract}
Background: The interspecies interactions in a biomethanation community play a vital role in substrate degradation and methane $\left(\mathrm{CH}_{4}\right)$ formation. However, the physiological and molecular mechanisms of interaction among the microbial members of this community remain poorly understood due to the lack of an experimentally tractable model system. In this study, we successfully established two coculture models combining the cellulose-degrading bacterium Clostridium cellulovorans 743B with Methanosarcina barkeri Fusaro or Methanosarcina mazei Gö1 for the direct conversion of cellulose to $\mathrm{CH}_{4}$.

Results: Physiological characterizations of these models revealed that the methanogens in both cocultures were able to efficiently utilize the products produced by C. cellulovorans during cellulose degradation. In particular, the simultaneous utilization of hydrogen, formate, and acetate for methanogenesis was observed in the C. cellulovoransM. barkeri cocultures, whereas monocultures of $M$. barkeri were unable to grow with formate alone. Enhanced cellulose degradation was observed in both cocultures, and the $\mathrm{CH}_{4}$ yield of the $\mathrm{C}$. cellulovorans-M. barkeri cocultures ( $0.87 \pm 0.02 \mathrm{~mol} \mathrm{CH}_{4} / \mathrm{mol}$ glucose equivalent) was among the highest compared to other coculture studies. A metabolic shift in the fermentation pattern of C. cellulovorans was observed in both cocultures. The expression levels of genes in key pathways that are important to the regulation and metabolism of the interactions in cocultures were examined by reverse transcription-quantitative PCR, and the expression profiles largely matched the physiological observations.

Conclusions: The physiological and molecular characteristics of the interactions of two $\mathrm{CH}_{4}$-producing cocultures are reported. Coculturing C. cellulovorans with $M$. barkeri or M. mazei not only enabled direct conversion of cellulose to $\mathrm{CH}_{4}$, but also stabilized $\mathrm{pH}$ for $\mathrm{C}$. cellulovorans, resulting in a metabolic shift and enhanced cellulose degradation. This study deepens our understanding of interspecies interactions for $\mathrm{CH}_{4}$ production from cellulose, providing useful insights for assembling consortia as inocula for industrial biomethanation processes.
\end{abstract}

Keywords: Methanogenesis, Dark fermentation, Coculture, Cellulose degradation, Transcriptome, Metabolism

\section{Background}

Biomethanation, a natural biological process by which organic materials are transformed into biogas, can be deployed for waste treatment and sustainable energy production $[1,2]$. This process has been widely applied in municipal sewage treatment to not only effectively reduce the volume and odor of volatile solids, but also

*Correspondence: patrick.kh.lee@cityu.edu.hk B5423-AC1, School of Energy and Environment, City University of Hong Kong, Tat Chee Avenue, Kowloon, Hong Kong produce methane $\left(\mathrm{CH}_{4}\right)$ as an energy resource to power treatment facilities [3]. As the worldwide demand for renewable energy increases, biomethanation of organic materials has an important role to play in our energy future [4].

The biomethanation process in nature relies on the microbial interactions between three main metabolic groups of anaerobes: fermentative, acetogenic, and methanogenic microorganisms [5-7]. The first two groups decompose complex organic matters to acetate, hydrogen 
$\left(\mathrm{H}_{2}\right)$, and carbon dioxide $\left(\mathrm{CO}_{2}\right)$, which are the key precursors for methanogenesis. Methanogens further convert these metabolites to $\mathrm{CH}_{4}$ by two major routes: the acetoclastic and $\mathrm{CO}_{2}$ reduction pathways [8]. Although methanogens are obligately dependent on the first two metabolic groups to supply substrates for growth, the two methanogenesis pathways can in turn affect their activities. First, $\mathrm{H}_{2}$ production by some bacteria is thermodynamically unfavorable; therefore, their growth is contingent on the $\mathrm{CO}_{2}$-reducing methanogens to maintain a low $\mathrm{H}_{2}$ partial pressure [9]. For example, the maintenance of a very low concentration of $\mathrm{H}_{2}$ in the ecosystem by the methanogens is essential for the catabolism of fatty acids by the obligate proton-reducing acetogenic bacteria Desulfovibrio vulgaris $[10,11]$. Second, the consumption of acetate by acetate-utilizing methanogens can help to maintain a $\mathrm{pH}$ close to neutral to support optimal metabolic activities of other members [2]. These illustrated interdependent relationships form the basis of many interactions that occur in a biomethanation community.

Because cellulosic materials are commonly found in nature, methanogens often exist concomitantly with cellulose-fermenting bacteria in anaerobic habitats, such as sediments, sewage digesters, and landfills [12-14]. Cellulose-fermenting bacteria hydrolyze the insoluble cellulose into end products-such as organic acids, $\mathrm{CO}_{2}$, and $\mathrm{H}_{2}$-which become carbon and energy sources for other members, including methanogens, within the microbial community. Because of this substrate dependency, the interactions between the cellulolytic bacteria and methanogens play a crucial role in shaping a biomethanation community. In order to gain insights into the metabolic functions of the cellulolytic-methanogenic communities, efforts have been made to study the interactions between cellulose-fermenting bacteria and $\mathrm{H}_{2}$ /formate/acetateconsuming methanogens in artificially constructed cultures. For example, Laube and Martin [15] studied cocultures of Acetivibrio cellulolyticus-Methanosarcina barkeri and M. barkeri-Desulfovibrio sp., as well as a triculture integrating A. cellulolyticus, M. barkeri, and Desulfovibrio sp. Their results showed that the methanogen was able to utilize the $\mathrm{H}_{2}$ and acetate produced by the cellulose-fermenting bacteria for $\mathrm{CH}_{4}$ production, resulting in improved $\mathrm{CH}_{4}$ production and a faster fermentation rate in the triculture. Nakashimada et al. [16] investigated cocultures of the anaerobic fungi Neocallimastix frontalis with a formate- and $\mathrm{H}_{2}$-utilizing methanogen (Methanobacterium formicicum) or an acetoclastic methanogen (Methanosaeta concilii), as well as a triculture incorporating $N$. frontalis, $M$. formicicum, and M. concilii. Their results demonstrated that whereas the coculture of $N$. frontalis-M. formicicum utilized formate and $\mathrm{H}_{2}$ and the coculture of $N$. frontalis-M. concilii utilized acetate for $\mathrm{CH}_{4}$ production, the triculture of $N$. frontalis, $M$. formicicum, and M. concilii was able to use formate, $\mathrm{H}_{2}$, and acetate for $\mathrm{CH}_{4}$ production. Robert et al. [17] investigated interspecies $\mathrm{H}_{2}$ transfer by employing cocultures of fibrolytic bacteria and the $\mathrm{H}_{2}$-utilizing colonic methanogen Methanobrevibacter smithii and observed that $\mathrm{H}_{2}$ utilization by the methanogen induced a metabolic shift in the cellulolytic strain. Sasaki et al. [18] incorporated $C$. clariflavum CL-1 and the hydrogenotrophic methanogen Methanothermobacter thermautotrophicus $\Delta \mathrm{H}$ under thermophilic conditions. They reported that the cellulose degradation efficiency and cell density of $C$. clariflavum CL-1 were significantly higher in the coculture than in the monoculture. Bauchop et al. [19] employed a rumen anaerobic fungus with a consortium of rumen methanogens for methanogenesis from cellulose and observed a metabolic shift in the fungus.

Although the aforementioned coculture and triculture studies have all demonstrated that $\mathrm{CH}_{4}$ can be successfully produced from products of cellulose hydrolysis by various methanogens, the simultaneous utilization of $\mathrm{H}_{2}$, formate, and acetate by a single methanogen in a coculture has not yet been reported. In addition, the molecular mechanism of the interactions between fermentative cellulose degraders and methanogens is also unclear; however, such an understanding is essential in order to shed light on key cellular regulation and metabolism during coculturing. For instance, gene expression of key pathways related to the metabolic shift in cellulolytic bacteria and the activity of methanogen is of great importance to understand the carbon and electron flows between these two organisms. In this study, we examined whether the metabolic versatile methanogen Methanosarcina barkeri Fusaro-which is potentially capable of utilizing $\mathrm{H}_{2}$, formate, and acetate for methanogenesis-can form a coculture with the cellulose-degrading bacterium Clostridium cellulovorans $743 \mathrm{~B}$, which is capable of producing all three methanogenesis precursors $\left(\mathrm{H}_{2}\right.$, formate, and acetate) as major fermentation metabolites. Meanwhile, Methanosarcina mazei Gö1, which possesses the ability to utilize $\mathrm{H}_{2}$ and acetate but not formate for methanogenesis, was also employed for coculturing with C. cellulovorans to enable comparison with the $C$. cellulovorans $-M$. barkeri cocultures. The genomes of C. cellulovorans, M. barkeri, and M. mazei [20-22] have all been fully sequenced, making the two cocultures genetically tractable in order to understand the molecular mechanisms of the interactions. The physiology of the two coculture models was characterized, and the expression levels of genes in key pathways in cocultures and monocultures were analyzed and compared. Overall, the results of this study provide insights into the interactions between the 
cellulolytic bacterium and the methanogens, and a comprehensive understanding of these interactions is crucial for engineering synthetic consortia for large-scale biomethanation processes to produce energy from renewable cellulosic biomass.

\section{Methods}

\section{Cultures and growth conditions}

The dark fermentative bacterium C. cellulovorans (ATCC\# 35296) was purchased from the American Type Culture Collection (ATCC, VA, USA), whereas the two methanogens-M. barkeri (DSM\# 804) and M. mazei (DSM\# 3647)-were purchased from the German Collections of Microorganisms and Cell Cultures (DSMZ, Germany). C. cellulovorans, M. barkeri, and M. mazei were first grown in the respective media recommended by the culture collections to revive the lyophilized cells. Subsequently, active inoculum $(5 \% \mathrm{vol} / \mathrm{vol})$ of C. cellulovorans was transferred to a defined medium (DCB-1) with $3 \mathrm{~g} / \mathrm{L}$ of cellulose as previously described [23] with the following modifications: $2 \mathrm{~g} / \mathrm{L}$ of yeast extract, $10 \mathrm{~g} / \mathrm{L}$ of sodium chloride, and $9.5 \mathrm{~g} / \mathrm{L}$ of magnesium sulfate were added, and $\mathrm{CO}_{2} / \mathrm{N}_{2}$ (20\%:80\%) filled the headspace. Active inocula $(10 \% \mathrm{vol} / \mathrm{vol})$ of M. barkeri and M. mazei were transferred to a defined high-salt medium [24] with $50 \mathrm{mM}$ of acetate and $\mathrm{CO}_{2} / \mathrm{N}_{2}(20 \%: 80 \%)$ in the headspace. After inoculation, the methanogens grown with acetate required about 6 months of acclimation before noticeable growth occurred, but thereafter the cultures could be routinely propagated every 2 weeks.

All monoculture and coculture experiments were carried out in $160-\mathrm{mL}$ serum bottles with $100 \mathrm{~mL}$ of the DCB-1 medium as described above and incubated at $35{ }^{\circ} \mathrm{C}$ without shaking. Monocultures of $C$. cellulovorans were grown with $3 \mathrm{~g} / \mathrm{L}$ of cellulose, whereas monocultures of M. barkeri and M. mazei were grown with $50 \mathrm{mM}$ of acetate. For coculture experiments, $3 \mathrm{~g} / \mathrm{L}$ of cellulose was amended as the only substrate, and $C$. cellulovorans and $M$. barkeri were inoculated at a cell ratio of 1.4:1, whereas C. cellulovorans and M. mazei were inoculated at a cell ratio of 1.7:1. The inoculum for each experiment was obtained from the mid-exponential growth phase of the respective monocultures. To examine whether monocultures of $M$. barkeri can grow with formate alone, active inoculum of $M$. barkeri grown with acetate was transferred to the DCB-1 medium and high-salt medium amended with $50 \mathrm{mM}$ of formate. In addition, to evaluate whether the presence of other methanogenesis precursors affected the consumption of formate by M. barkeri, active inoculum of $M$. barkeri grown with acetate was transferred to the DCB-1 medium amended with all three methanogenesis precursors $(10 \mathrm{mM}$ of formate, $3 \mathrm{mM}$ of acetate, and $0.95 \mathrm{mmol}$ of $\mathrm{H}_{2}$ ), and to the DCB-1 medium with $3 \mathrm{mM}$ of acetate and $0.95 \mathrm{mmol}$ of $\mathrm{H}_{2}$ as control. These conditions mimicked the concentrations of the three methanogenesis precursors in the C. cellulovorans monocultures at mid-exponential growth phase. All experiments were performed in triplicate.

\section{Analytical analyses}

The total volume of gas accumulated at each time point was measured. A needle connected to a disposable syringe was inserted through the stopper into the headspace when taking measurement. The volume in the calibrated syringe after plunger displacement was the gas accumulated. The concentrations of $\mathrm{H}_{2}$ and $\mathrm{CH}_{4}$ were sampled using a gas-tight syringe (Hamilton, NV, USA) and analyzed using a gas chromatograph (GC-2010, Shimadzu, Japan) equipped with a thermal conductivity detector and a flame ionization detector. The column (30 $\mathrm{m} \times 0.53 \mathrm{~mm}$ inner diameter) for $\mathrm{H}_{2}$ detection was a $5 \mathrm{~A}$ molecular sieve (Restek, PA, USA) and the column (30 $\mathrm{m} \times 0.53 \mathrm{~mm}$ inner diameter) for $\mathrm{CH}_{4}$ detection was a Rt-QS-BOND column (Restek, PA, USA), both with helium as a carrier gas. The column temperature was $35^{\circ} \mathrm{C}$, the detector temperature was $200{ }^{\circ} \mathrm{C}$, and the injector temperature was $120{ }^{\circ} \mathrm{C}$ for both analyses. The $\mathrm{CO}_{2}$ produced by $\mathrm{C}$. cellulovorans [25] was not determined since excess $\mathrm{CO}_{2}$ was provided by filling the headspace of the culture bottles with $\mathrm{CO}_{2} / \mathrm{N}_{2}(20 \%: 80 \%)$ and $2.5 \mathrm{~g} / \mathrm{L}$ of sodium bicarbonate was added as part of the DCB-1 medium. The concentrations of gas $\left(C_{G}\right)$ were converted to total mole $(n)$ of $\mathrm{H}_{2}$ or $\mathrm{CH}_{4}$ in each serum bottle using the corresponding Henry's constant $(H)$ [26] according to the following material balance: $n=C_{\mathrm{G}} V_{\mathrm{G}}+C_{\mathrm{G}} H V_{\mathrm{L}}$, where $V_{\mathrm{G}}$ and $V_{\mathrm{L}}$ are the gas and liquid volumes in a serum bottle, respectively. Two mLs of sample were withdrawn from each culture bottle to measure $\mathrm{pH}$, the concentrations of metabolic products and cellulose, and the cell density as described previously [27]. Glucose equivalent is a measure of the amount of reducing sugars present in a sugar product, relative to glucose [28].

\section{Cell morphology analysis}

The morphology of cells in the cocultures and monocultures was visualized by scanning electron microscopy (SEM). SEM analysis was performed as previously described [29] with some modifications. Samples were collected from biological triplicate during the mid-exponential growth phase according to the amount of $\mathrm{H}_{2}$ or $\mathrm{CH}_{4}$ produced and pooled prior to cell fixation. Cells were fixed for $24 \mathrm{~h}$ at $4{ }^{\circ} \mathrm{C}$ in $2 \% \mathrm{vol} / \mathrm{vol}$ glutaraldehyde in $0.1 \mathrm{M}$ sodium cacodylate buffer ( $\mathrm{pH}$ 7.2). Subsequently, the cells were washed with $0.1,0.05$, and $0.025 \mathrm{M}$ of cacodylate buffers for 15 min each. Samples were then dehydrated through a gradient of ethanol concentrations (50, 
70 , and $90 \% \mathrm{vol} / \mathrm{vol}$ ) for $15 \mathrm{~min}$ each, then washed three times with $100 \%$ ethanol and acetone for 15 min each. Ethanol-acetone dehydrated samples were critical-point dried in liquid $\mathrm{CO}_{2}$ with a Bal-Tec CPD 030 critical-point drier (Bal-Tec, Balzers, Liechtenstein). With the use of carbon tape, the samples were stuck on aluminum stubs. The dehydrated samples were observed under a Philips XL30 ESEM FEG environmental SEM (Philips Electronics, Netherlands) after being sputter coated with gold palladium using a Bal-Tec SCD 050 sputter coater (Bal-Tec, Balzers, Liechtenstein).

\section{Cell density analysis}

Genomic DNA extraction and absolute quantification of cell number of the respective organisms in each culture with quantitative PCR (qPCR) were performed as described previously [27]. C. cellulovorans was quantified by targeting its cellulase gene (Gene ID: 9607758) with forward primer $5^{\prime}$-ACAGCGCAAGATGGCTTCTA-3' and reverse primer 5'-GCTGTAGCTCCCCATTGAGT-3', M. barkeri by its formate dehydrogenase subunit alpha gene (Gene ID: 3625978) with forward primer 5'-TCGGACCCGGATCTAAACAA-3' and reverse primer $5^{\prime}$-ATTGGTCTGGGTCCCGTTCT-3', and $M$. mazei by its methyl-coenzyme $M$ reductase gene (Gene ID: 1479582) with forward primer $5^{\prime}$-ATGCAGCAGATGTGGGATGAC-3' and reverse primer 5'-CGACCATCATTTCCTGAACCA- $3^{\prime}$. One copy of the target gene was found in each respective genome. All primers in this study were designed using Primer Express 3.0 (Applied Biosystems, CA, USA) and their specificity was verified.

\section{RNA extraction}

Duplicate monocultures or cocultures were prepared for mRNA relative quantification analysis. Cells were collected during the mid-exponential growth phase, and total RNA was extracted using the protocol described previously [30]. The purity and concentration of the total RNA were determined by a Nano Drop 2000 spectrophotometer (Thermo Fisher Scientific, MA, USA). For all samples, $\mathrm{A}_{260} / \mathrm{A}_{280}$ ratios ranged from 2.0 to 2.1, and concentrations were above $91 \mathrm{ng} / \mu \mathrm{L}$. The integrity and quality of the total RNA were further assessed on a bioanalyzer 2100 (Agilent, CA, USA) with the Agilent RNA 6000 Pico kit (Agilent, CA, USA) according to the manufacturer's instructions. Only samples with an RNA integrity number (RIN) above 7.5 were used for downstream analyses.

\section{Reverse transcription (RT)-qPCR}

To examine the cellular regulation of key pathways of the cocultures and monocultures, 37 genes were selected and analyzed by RT-qPCR using specific primers (Additional file 1: Table S1) for relative mRNA quantification.
The genes of C. cellulovorans are designated as "Clocel," M. barkeri as "Mbar A," and M. mazei as "MM." Total RNA was reverse-transcribed into complementary DNA (cDNA) with random hexamers using the SuperScript III (Invitrogen, CA, USA) reverse transcriptase according to the manufacturer's instructions. For negative reverse transcriptase controls to verify the absence of genomic DNA, diethylpyrocarbonate-treated water replaced the reverse transcriptase. Amplification of the synthesized cDNA (two technical replicates per biological replicate) and negative controls was performed on a StepOne Plus Real-Time PCR System (Applied Biosystems, CA, USA) using the PowerUp ${ }^{\text {TM }}$ SYBR Green Master Mix (Applied Biosystems, CA, USA) according to the manufacturer's instructions and default thermal-cycling conditions.

Comparative threshold $(\mathrm{Ct})$ differences between cocultures and monocultures were calculated using averages of quadruplicate samples. The fold difference for each target gene was calculated using the $2^{-\Delta \Delta C t}$ method [31] (reported as ratio of coculture/monoculture). Because peptidyl-prolyl isomerase (cyclophilin) is considered a stable housekeeping gene [32, 33], and our previous experiments with $C$. cellulovorans [30] validated the expression of this gene was unaffected by experimental treatment, peptidyl-prolyl isomerase was used as an internal control gene for normalization for C. cellulovorans. On the other hand, the glyceraldehyde dehydrogenase ( $g a p)$ gene of $M$. barkeri and M. mazei [34] was used as an internal control gene for normalization. Specific primers for the three internal control genes are listed in Additional file 1: Table $\mathrm{S} 2$. The statistical significance of the expression ratio of each gene between two conditions (cocultures versus monocultures) was analyzed using the Student's $t$ test. The standard deviation of the fold changes across replicates of each gene was on average equal to an absolute value of 0.6 fold. An absolute value of the fold change $\geq 1.2$ (twice the average standard deviation across replicates) and a $p$ value $<0.05$ were set as thresholds to identify genes that were differentially expressed between cocultures and monocultures. Upregulation (a positive expression ratio) refers to a higher relative molar concentration of the transcripts of a particular gene of $C$. cellulovorans, $M$. barkeri, or $M$. mazei in cocultures relative to the respective monocultures, and downregulation (a negative expression ratio) refers to a lower relative molar concentration of transcripts in cocultures. The expression ratios of the differentially expressed genes (|fold change $\mid \geq 1.2$ and $p$ value $<0.05$ ) are shown as heat maps.

\section{Results}

Methanogenesis and cellulose utilization

$\mathrm{CH}_{4}$ and $\mathrm{H}_{2}$ production by cocultures of $\mathrm{C}$. cellulovorans $-M$. barkeri and C. cellulovorans $-M$. mazei and 
by monocultures of $C$. cellulovorans were examined by amending $3 \mathrm{~g} / \mathrm{L}$ of cellulose as the sole substrate. Coculturing C. cellulovorans with either $M$. barkeri or $M$. mazei both led to methanogenesis during the cultivation period, and linear $\mathrm{CH}_{4}$ production was observed from day 2 onwards (Fig. 1a). The total duration of $\mathrm{CH}_{4}$ production for $C$. cellulovorans $-M$. barkeri was longer than that for C. cellulovorans-M. mazei (17 versus 10 days), and the final total amount of $\mathrm{CH}_{4}$ produced in C. cellulovorans $-M$. barkeri was substantially higher than that produced in C. cellulovorans $-M$. mazei $(1.5 \pm 0.07 \mathrm{mmol}$ versus $0.7 \pm 0.09 \mathrm{mmol})$. Monocultures of $M$. barkeri and M. mazei grown on $50 \mathrm{mM}$ acetate produced $2.8 \pm 0.1 \mathrm{mmol}$ and $2.5 \pm 0.09 \mathrm{mmol}$ of $\mathrm{CH}_{4}$, respectively (Additional file 1: Figure S1). On the other hand, $0.3 \pm 0.01 \mathrm{mmol}$ of $\mathrm{CH}_{4}$ accumulated in monocultures of $M$. barkeri grown with $10 \mathrm{mM}$ formate, $3 \mathrm{mM}$ acetate, and $0.95 \mathrm{mmol} \mathrm{H}_{2}$, whereas $0.2 \pm 0.01 \mathrm{mmol}$ of $\mathrm{CH}_{4}$ accumulated in monocultures of $M$. barkeri grown with $3 \mathrm{mM}$ acetate and $0.95 \mathrm{mmol} \mathrm{H}_{2}$. In these monocultures, $\mathrm{H}_{2}$ was depleted gradually during the cultivation period (Additional file 1: Figures $\mathrm{S} 2, \mathrm{~S} 3$ ). $\mathrm{No}^{\mathrm{CH}_{4}}$ was observed in the monocultures of $M$. barkeri grown with formate alone. As opposed to $\mathrm{CH}_{4}$ production, $1.5 \pm 0.08 \mathrm{mmol}$ of $\mathrm{H}_{2}$ accumulated in monocultures of $C$. cellulovorans, whereas no $\mathrm{H}_{2}$ was detected in the cocultures throughout the cultivation period.

Cellulose degradation was observed in both cocultures and monocultures of C. cellulovorans. Coculturing C. cellulovorans with either M. barkeri (+13.8\%) or M. mazei $(+8.9 \%)$ both resulted in enhanced cellulose degradation relative to monocultures of $C$. cellulovorans (Fig. 1b). At the end of the incubation period, a small amount of cellulose remained. This is likely due to the acidic $\mathrm{pH}$, as a result of volatile fatty acids (VFAs) accumulation, inhibiting the metabolic activity of the dark fermenters [35]. No growth or cellulose degradation was observed in the controls of $M$. barkeri and $M$. mazei monocultures grown on cellulose. Corresponding to the higher $\mathrm{CH}_{4}$ production and more complete cellulose degradation, the $\mathrm{CH}_{4}$ yield and production rate of C. cellulovorans-M. barkeri were nearly two times higher than those of C. cellulovorans $-M$. mazei after taking into account the amount of cellulose consumed (Table 1). Together, these results indicate that coculturing C. cellulovorans with either $M$. barkeri or $M$. mazei not only enabled $\mathrm{CH}_{4}$ production from cellulose but also enhanced cellulose degradation in comparison to monocultures of $C$. cellulovorans. $C$. cellulovorans $-M$. barkeri exhibited a stronger ability of methanogenesis than C. cellulovorans-M. mazei in terms of $\mathrm{CH}_{4}$ yield and transformation rate.

\section{Fermentation products and $\mathrm{pH}$}

Monocultures of C. cellulovorans mainly fermented cellulose to $\mathrm{H}_{2}, \mathrm{CO}_{2}$, and VFAs, including formate, acetate, butyrate, and lactate (Additional file 1: Table S3). Production of VFAs by C. cellulovorans monocultures increased gradually to maximum accumulated concentrations of $9.1 \pm 0.4 \mathrm{mM}$ of formate, $3.0 \pm 0.2 \mathrm{mM}$ of acetate, $9.0 \pm 0.3 \mathrm{mM}$ of butyrate, and $3.6 \pm 0.1 \mathrm{mM}$ of lactate (Fig. 2). However, the presence of methanogens in cocultures led to VFAs consumption and induced a change in the fermentation pattern of $C$. cellulovorans, resulting in different VFA concentrations in cocultures relative to
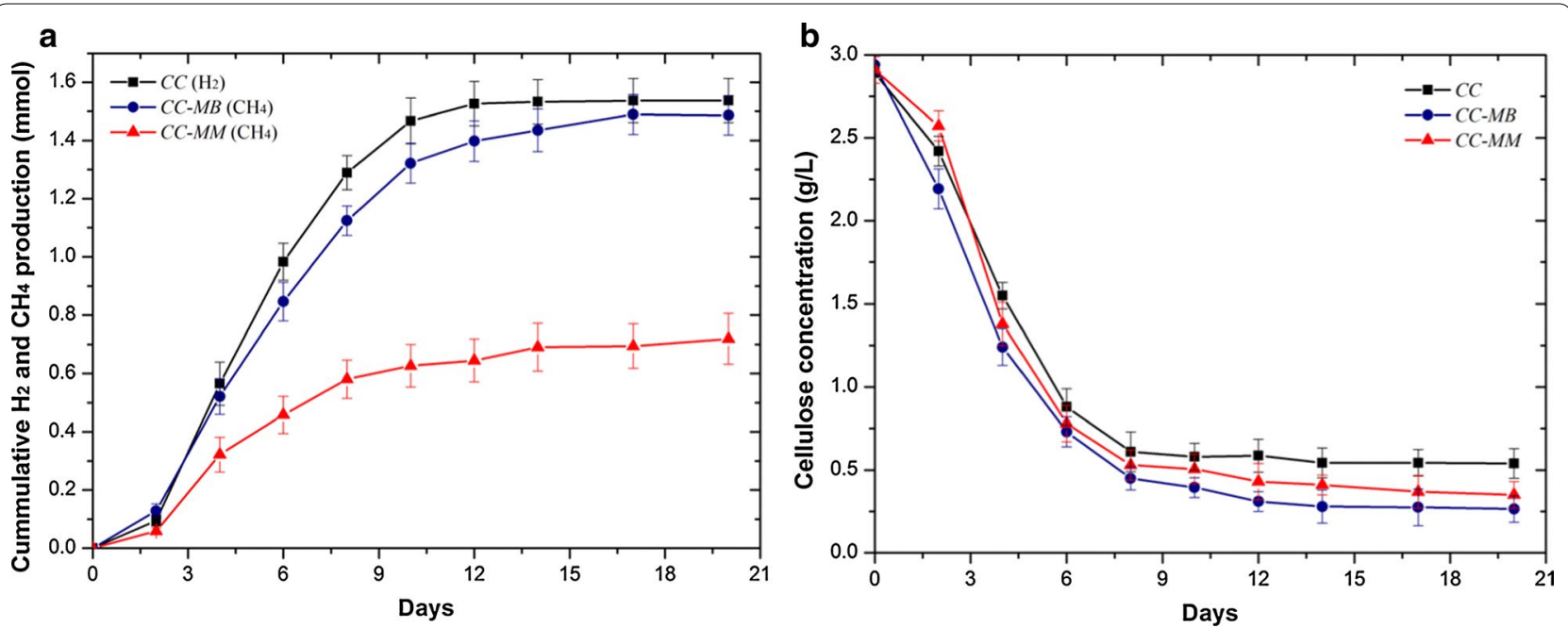

Fig. 1 a Comparison of $\mathrm{H}_{2}$ and $\mathrm{CH}_{4}$ production and $\mathbf{b}$ cellulose degradation for cocultures of C. cellulovorans-M. barkeri (CC-MB) and C. cellulovorans-M. mazei (CC-MM) and monocultures of C. cellulovorans (CC). Each data point is an average of biological triplicate and error bars represent one standard deviation 
Table 1 Mass and rate of cellulose consumption, and yield and rate of $\mathrm{H}_{2}$ and $\mathrm{CH}_{4}$ production

\begin{tabular}{lllllll}
\hline Cultures & $\begin{array}{l}\text { Cellulose } \\
\text { consumed } \\
(\mathbf{m g})\end{array}$ & $\begin{array}{l}\mathrm{H}_{\mathbf{2}} \text { yield }\left(\mathrm{mol} \mathrm{H}_{\mathbf{2}} /\right. \\
\text { mol glucose } \\
\text { equivalent) }\end{array}$ & $\begin{array}{l}\mathrm{CH}_{\mathbf{4}} \text { yield }\left(\mathrm{mol} \mathrm{CH}_{\mathbf{4}} /\right. \\
\text { mol glucose } \\
\text { equivalent) }\end{array}$ & $\begin{array}{l}\text { Cellulose } \\
\text { degradation } \\
\text { rate (mg/day) }\end{array}$ & $\begin{array}{l}\mathrm{H}_{\mathbf{2}} \text { production } \\
\text { rate (mmol/day) }\end{array}$ & $\begin{array}{l}\mathrm{CH}_{\mathbf{4}} \text { production } \\
\text { rate }(\mathbf{m m o l} / \mathrm{day})\end{array}$ \\
\hline $\begin{array}{l}\text { C. cellulovorans } \\
\begin{array}{l}\text { C. cellulovorans-M. } \\
\text { barkeri }\end{array}\end{array}$ & $235 \pm 8$ & $1.02 \pm 0.03$ & - & $117 \pm 4$ & $0.077 \pm 0.004$ & - \\
$\begin{array}{l}\text { C. cellulovorans-M. } \\
\text { mazei }\end{array}$ & $267 \pm 16$ & - & $0.87 \pm 0.02$ & $133 \pm 8$ & - & $0.074 \pm 0.003$ \\
\hline
\end{tabular}

Data are the average ( \pm one standard derivation) of biological triplicate
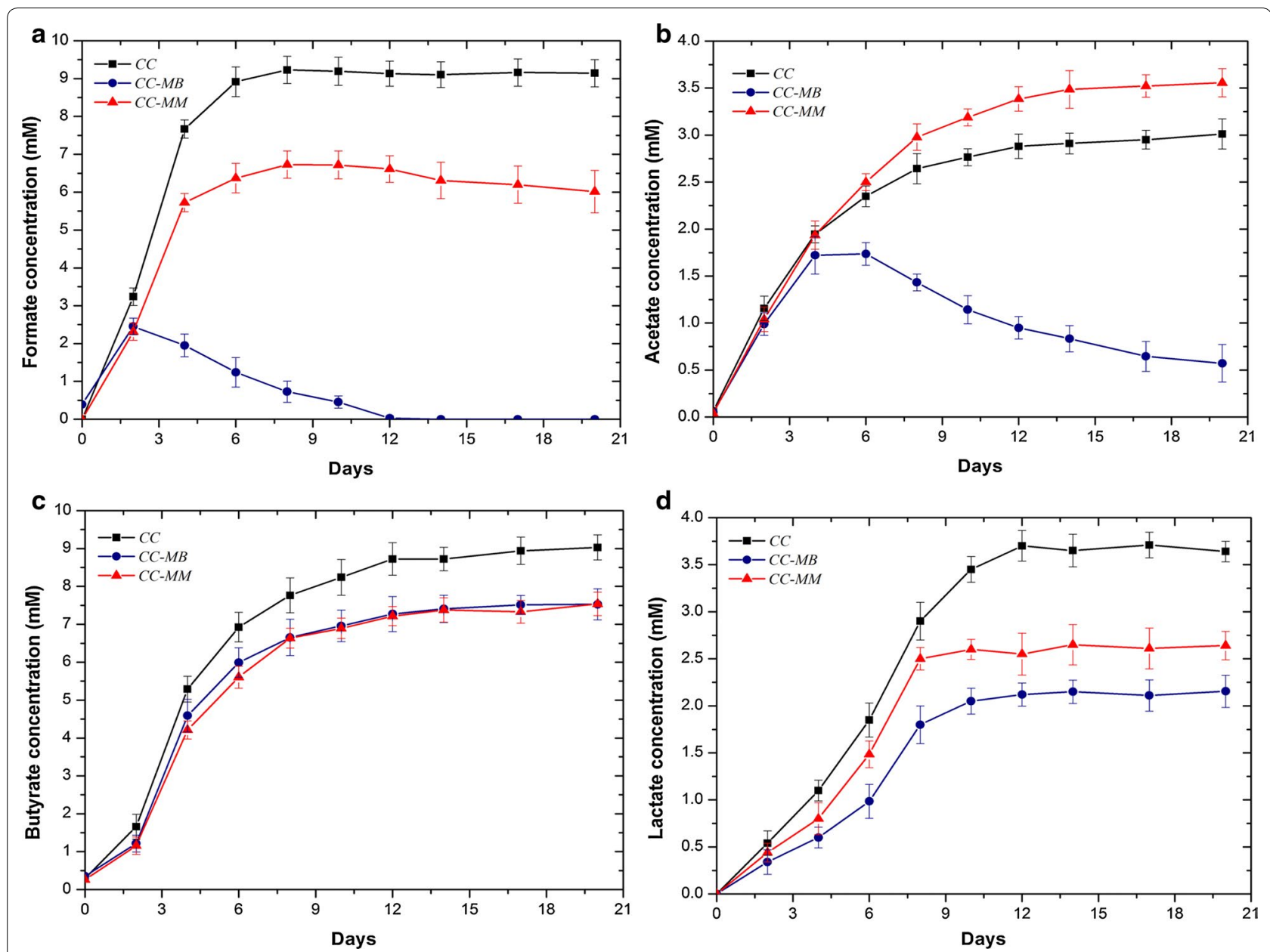

Fig. 2 Comparison of VFA concentrations (a formate, $\mathbf{b}$ acetate, $\mathbf{c}$ butyrate, $\mathbf{d}$ lactate) for cocultures of C. cellulovorans-M. barkeri (CC-MB) and C. cellulovorans-M. mazei (CC-MM) and monocultures of C. cellulovorans (CC). Each data point is an average of biological triplicate and error bars represent one standard deviation

the C. cellulovorans monocultures. For the cocultures of C. cellulovorans $-M$. barkeri, formate and acetate only transiently accumulated during the cultivation period. Formate concentration reached its peak of $2.5 \pm 0.2 \mathrm{mM}$ on day 2 , then decreased rapidly until depletion on day 12 (Fig. 2a). Similarly, the acetate concentration also decreased progressively until near depletion after reaching its maximum concentration of $1.7 \pm 0.1 \mathrm{mM}$ on day 6 (Fig. 2b). The depletion of formate and acetate indicates their utilization via methanogenesis by $M$. barkeri. In contrast, net reduction in the concentrations of butyrate and lactate concentrations was not observed during the cultivation period. However, the final concentrations of butyrate and lactate were both lower in 
C. cellulovorans-M. barkeri than in the C. cellulovorans monocultures (Fig. 2c, d). On the other hand, only $1.5 \pm 0.4 \mathrm{mM}$ of formate and insignificant amount of acetate were consumed in monocultures of $M$. barkeri grown with $10 \mathrm{mM}$ formate, $3 \mathrm{mM}$ acetate, and $0.95 \mathrm{mmol} \mathrm{H}_{2}$. Similarly, insignificant amount of acetate was consumed in monocultures of $M$. barkeri grown with $3 \mathrm{mM}$ acetate and $0.95 \mathrm{mmol} \mathrm{H}_{2}$ (Additional file 1: Figures S2, S3). For the cocultures of C. cellulovorans-M. mazei, neither formate nor acetate depletion was observed during the cultivation period. However, whereas the final formate concentration in C. cellulovorans-M. mazei was lower than in C. cellulovorans monocultures, the final acetate concentration in C. cellulovorans-M. mazei was higher by $18 \%$ (Fig. 2a, b), and the final concentrations of butyrate and lactate were also lower in C. cellulovoransM. mazei (Fig. 2c, d).

The $\mathrm{pH}$ of the C. cellulovorans monocultures decreased rapidly from the initial $\mathrm{pH}$ of $7.5 \pm 0.02$ to $6.1 \pm 0.05$, but the change in the cocultures of $C$. cellulovorans-M. barkeri and C. cellulovorans-M. mazei was smaller and more gradual (Fig. 3). The more stabilized $\mathrm{pH}$ of the cocultures compared to the C. cellulovorans monocultures is likely due to the consumption of VFAs by the methanogens and the change in fermentation pattern of C. cellulovorans in the cocultures. In addition, corresponding to the depletion of formate and acetate and a lower lactate concentration, the final $\mathrm{pH}$ of C. cellulovorans $-M$. barkeri $(\mathrm{pH}$ $6.7 \pm 0.06)$ was higher than that of $C$. cellulovorans $-M$. mazei (pH 6.4 \pm 0.05$)$.

\section{Cell growth and culture morphology}

Cell growth of M. barkeri and M. mazei in cocultures was quantified by qPCR (Fig. 4a), and cell morphology was

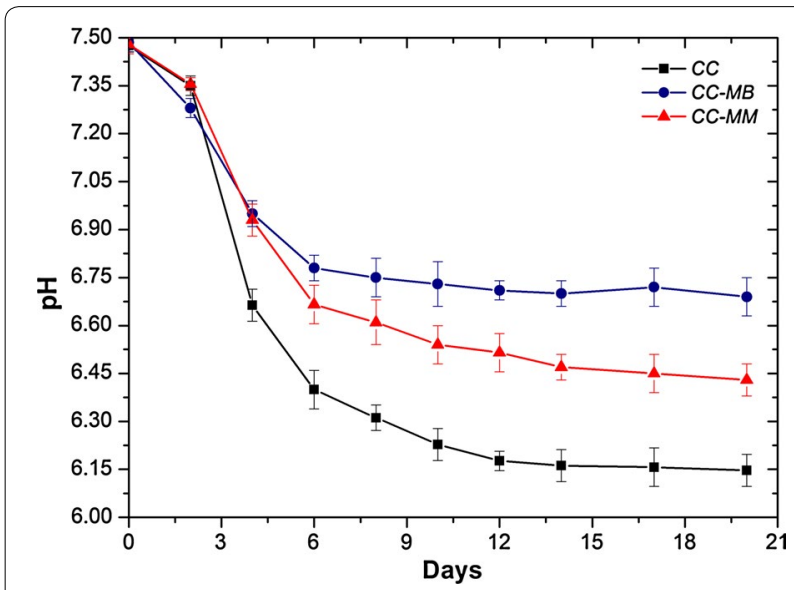

Fig. 3 Comparison of $\mathrm{pH}$ for cocultures of C. cellulovorans-M. barkeri (CC-MB) and C. cellulovorans-M. mazei (CC-MM) and monocultures of $C$. cellulovorans (CC). Each data point is an average of biological triplicate and error bars represent one standard deviation visualized by SEM (Fig. 4b, c). In cocultures, M. barkeri and M. mazei showed steady growth, reaching the stationary phase by day 8 (Fig. 4a). Compared to the monocultures of $M$. barkeri and M. mazei grown on acetate, $M$. barkeri and M. mazei in cocultures grew faster with a shorter lag phase. The cell yields of $M$. barkeri and $M$. mazei in cocultures were $3.1 \times 10^{13} \pm 4.5 \times 10^{12}$ cells/ $\mathrm{mol}$ of $\mathrm{CH}_{4}$ and $4.3 \times 10^{13} \pm 7.9 \times 10^{12}$ cells $/ \mathrm{mol}$ of $\mathrm{CH}_{4}$ respectively, whereas $M$. barkeri and $M$. mazei in monocultures were $3.5 \times 10^{13} \pm 3.2 \times 10^{12}$ cells $/ \mathrm{mol}$ of $\mathrm{CH}_{4}$ and $3.3 \times 10^{13} \pm 3.3 \times 10^{12} \mathrm{cells} / \mathrm{mol}$ of $\mathrm{CH}_{4}$, respectively. C. cellulovorans in both monocultures and cocultures grew to a higher final cell concentration compared to the methanogens. However, unlike the different cell growth rates observed for the methanogens between monocultures and cocultures, the presence of methanogens did not result in significant differences in cell growth for C. cellulovorans between monocultures and cocultures (Fig. 4a). The C. cellulovorans growth yield in monocultures was $2.0 \times 10^{12} \pm 8.0 \times 10^{11}$ cells/g of cellulose, whereas in cocultures of $C$. cellulovorans $-M$. barkeri and C. cellulovorans $-M$. mazei, it was $2.0 \times 10^{12} \pm 7.2 \times 10^{11}$ cells/g of cellulose and $1.9 \times 10^{12} \pm 6.4 \times 10^{11} \mathrm{cells} / \mathrm{g}$ of cellulose respectively. Interestingly, when grown in cocultures, C. cellulovorans and M. barkeri were observed to form aggregates, whereas C. cellulovorans and M. mazei existed as distinct separate cells (Fig. 4b, c).

\section{Expression of genes in pathways}

Based on the physiological results of the cocultures, a number of pathways that are important to the regulation and metabolism of the interactions between $C$. cellulovorans and $M$. barkeri or C. cellulovorans and M. mazei were investigated in detail (Figs. 5a, 6a). In order to examine how cells regulate these pathways, 17 C. cellulovorans genes, 13 M. barkeri genes, and 7 M. mazei genes encoding key enzymes within the respective pathways were analyzed by RT-qPCR. The fold changes of cocultures relative to their respective monocultures for these 37 selected genes are shown in Additional file 1: Tables S4, S5, S6. Genes with an absolute value of fold change $\geq 1.2$ and a $p$ value $<0.05$ were considered as differentially expressed to infer the regulation of the pathways (Figs. 5b, 6b).

For C. cellulovorans in the C. cellulovorans-M. barkeri cocultures (Fig. 5a, b), two out of three genes encoding cellulase (Clocel 3359 and Clocel 0912), the gene encoding glycoside hydrolase (Clocel 3111) related to cellulose degradation, and the genes encoding hydrogenase $(\mathrm{Hyd})$ (Clocel 4097, Clocel 3813, and Clocel 1155) related to $\mathrm{H}_{2}$ production were all upregulated. The two genes (Clocel 1684 and Clocel 2840) encoding the pyruvate:ferredoxin oxidoreductase (PFOR) within the pathway of pyruvate 


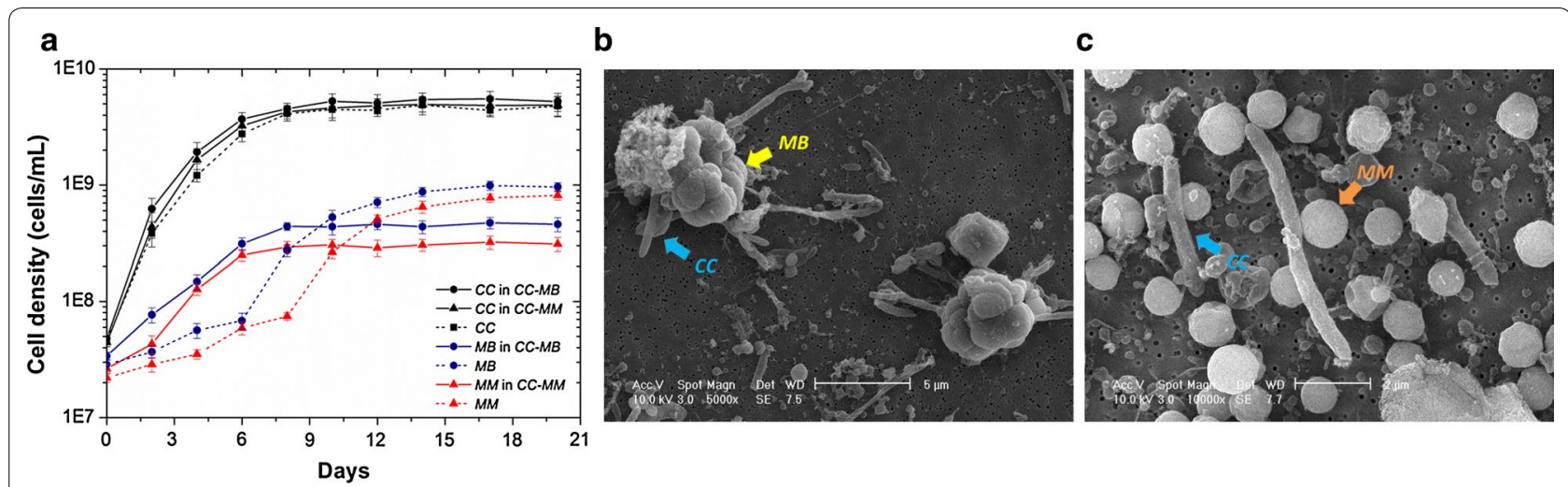

Fig. 4 a Comparison of cell growth for cocultures of C. cellulovorans-M. barkeri (CC-MB) and C. cellulovorans-M. mazei (CC-MM) and monocultures of C. cellulovorans (CC), M. barkeri (MB), and M. mazei (MM). Each data point is an average of biological triplicate and error bars represent one standard deviation. Scanning electron microscopy image of the $\mathbf{b} C C-M B$ coculture and $\mathbf{c} C C-M M$ coculture

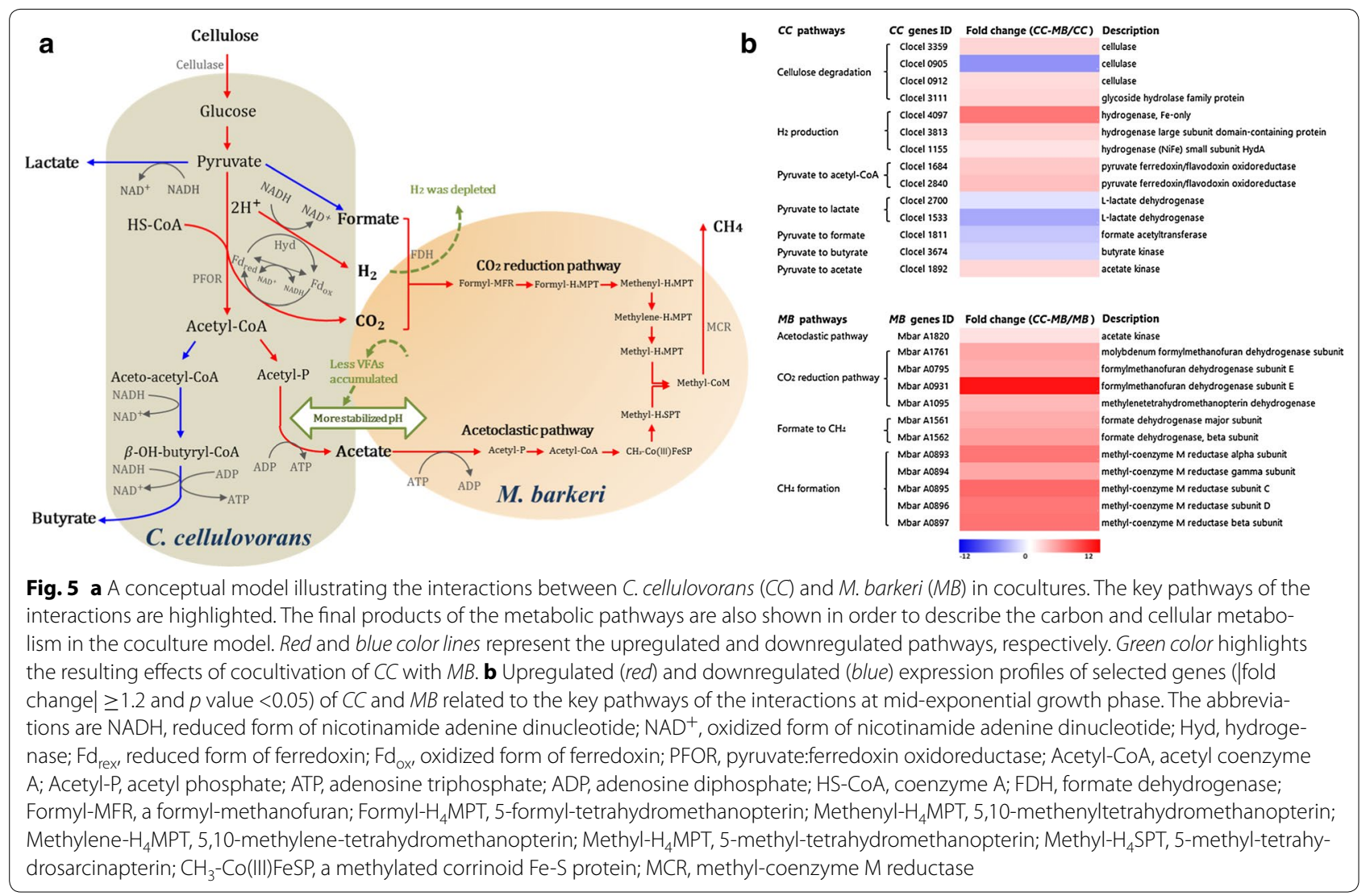

to acetyl coenzyme A (acetyl-CoA) were upregulated. For VFA biosynthesis, the gene (Clocel 1892) encoding acetate kinase for catalyzing pyruvate to acetate was upregulated, whereas the gene (Clocel 3674) encoding butyrate kinase within the pathway of pyruvate to butyrate, the gene (Clocel 1811) encoding formate acetyltransferase within the pathway of pyruvate to formate, and the genes
(Clocel 2700 and Clocel 1533) encoding L-lactate dehydrogenase within the pathway of pyruvate to lactate were all downregulated.

For $M$. barkeri in the cocultures, the gene (Mbar A1820) encoding acetate kinase within the acetoclastic pathway, the genes (Mbar A1761, Mbar A0795, Mbar A0931, and Mbar A1095) encoding formylmethanofuran 


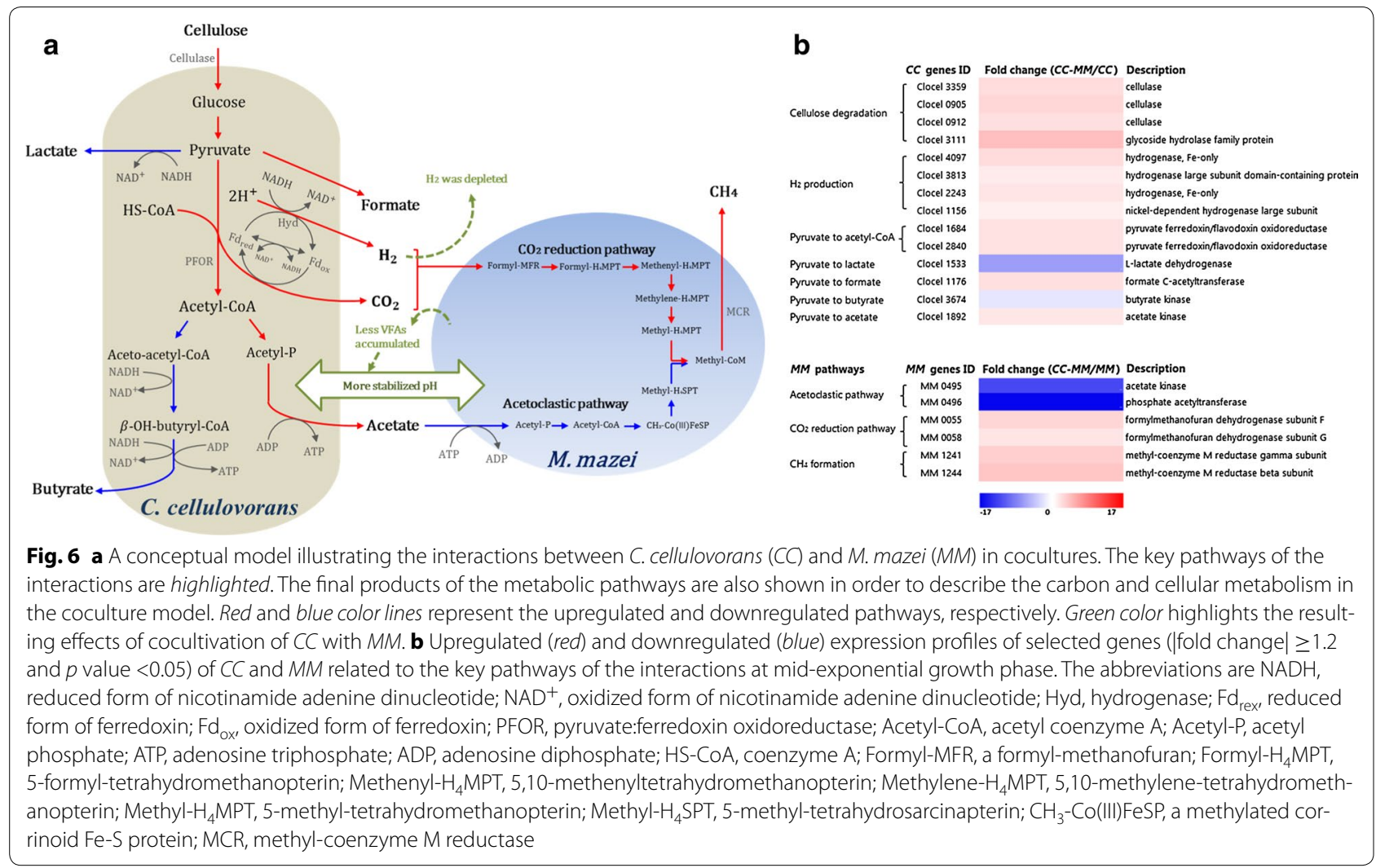

dehydrogenase and methylene-tetrahydromethanopterin dehydrogenase within the $\mathrm{CO}_{2}$ reduction pathway, the genes (Mbar A0893-0897) encoding the methyl-coenzyme $M$ reductase (MCR) - which catalyzes the final step in the formation of $\mathrm{CH}_{4}$-and the genes (Mbar A1561$1562)$ encoding formate dehydrogenase (FDH) were all upregulated.

For $C$. cellulovorans in the $C$. cellulovorans-M. mazei cocultures (Fig. 6a, b), the genes encoding cellulase (Clocel 3359, Clocel 0905, and Clocel 0912), glycoside hydrolase (Clocel 3111), and Hyd (Clocel 4097, Clocel 3813, Clocel 2243, and Clocel 1156) were all upregulated. The two genes (Clocel 1684 and Clocel 2840) encoding the PFOR were also upregulated. For VFA biosynthesis, the gene (Clocel 1892) encoding acetate kinase and the gene (Clocel 1176) encoding formate acetyltransferase were upregulated, whereas the gene (Clocel 3674) encoding butyrate kinase and the gene (Clocel 1533) encoding L-lactate dehydrogenase were downregulated in the $C$. cellulovorans-M. mazei cocultures.

For $M$. mazei in the cocultures, the genes (MM 0495-0496) encoding acetate kinase and phosphate acetyltransferase within the acetoclastic pathway were downregulated, and the genes (MM 0055 and MM 0058) encoding enzymes of the $\mathrm{CO}_{2}$ reduction pathway and the genes (MM 1241 and MM 1244) encoding the MCR were upregulated.

\section{Discussion}

\section{Coculturing $C$. cellulovorans with $M$. barkeri or M. mazei enabled direct conversion of cellulose to $\mathrm{CH}_{4}$}

Previous studies $[25,36]$ have shown that the cellulolytic bacterium $C$. cellulovorans is capable of fermenting cellulose to $\mathrm{H}_{2}, \mathrm{CO}_{2}$, and VFAs-including formate, acetate, butyrate, and lactate as the major metaboliteswhereas genomic and physiological studies [21, 37-39] have demonstrated that $M$. barkeri and $M$. mazei possess the ability to couple growth and $\mathrm{CH}_{4}$ generation by the acetoclastic and the $\mathrm{CO}_{2}$ reduction pathways. Although $M$. barkeri has never been reported to utilize formate for growth in pure cultures, genomic studies [21] have revealed the presence of genes (Mbar A1561-1562) encoding the FDH, suggesting that $M$. barkeri has the potential to utilize formate for methanogenesis. In this study, coculturing $C$. cellulovorans with either $M$. barkeri or $M$. mazei both enabled $\mathrm{CH}_{4}$ production from cellulose and enhanced cellulose degradation compared to monocultures of $C$. cellulovorans. Surprisingly, in addition to $\mathrm{H}_{2}$ and acetate consumption, formate was also consumed in the $C$. cellulovorans $-M$. barkeri cocultures. 
This demonstrates that $M$. barkeri is able to simultaneously utilize the three precursors $\left(\mathrm{H}_{2}\right.$, formate, and acetate) for methanogenesis. Consistent with previous results [21], we observed no growth of $M$. barkeri in monocultures when grown with $50 \mathrm{mM}$ of formate alone after 9 months. Moreover, we mimicked the conditions of the C. cellulovorans-M. barkeri cocultures by artificially providing monocultures of $M$. barkeri with all three methanogenesis precursors $(10 \mathrm{mM}$ of formate, $3 \mathrm{mM}$ of acetate, and $0.95 \mathrm{mmol}$ of $\mathrm{H}_{2}$ ). However, without the presence of $C$. cellulovorans, neither formate nor acetate consumption was significant (only $1.5 \pm 0.4 \mathrm{mM}$ of formate, which is less than $15 \%$ of the total amount provided, and insignificant amount of acetate were consumed), though $0.95 \mathrm{mmol}$ of $\mathrm{H}_{2}$ was depleted gradually during the cultivation period (no $\mathrm{H}_{2}$ accumulation was measured in the cocultures) (Additional file 1: Figure S2). The insignificant consumption of acetate might be due to the presence of the added $\mathrm{H}_{2}$ since the $0.95 \mathrm{mmol}$ of added $\mathrm{H}_{2}$ was not exhausted immediately. An inhibitory effect of $\mathrm{H}_{2}$ on the acetoclastic methanogenesis in Methanosarcina spp. has previously been reported [40]. Although the cumulative $\mathrm{CH}_{4}$ production of $M$. barkeri monocultures grown with the three methanogenesis precursors was higher than $M$. barkeri monocultures grown with acetate and $\mathrm{H}_{2}(0.3 \pm 0.01 \mathrm{mmol}$ versus $0.2 \pm 0.01 \mathrm{mmol}$ ) (Additional file 1: Figures S2, S3), it is significantly less than the C. cellulovorans $-M$. barkeri cocultures. The increase in cell density of the $M$. barkeri monocultures grown with the three methanogenesis precursors over the course of the experiment is also significantly lower than the $M$. barkeri in the C. cellulovorans $-M$. barkeri cocultures $\left(7.5 \times 10^{7} \pm 2.9 \times 10^{7}\right.$ cells/ $\mathrm{mL}$ versus $4.3 \times 10^{8} \pm 6.3 \times 10^{7}$ cells $/ \mathrm{mL}$ ) (Additional file 1: Figure S4). These results indicate that monocultures of $M$. barkeri did not grow as robustly as the $M$. barkeri in the cocultures even though similar methanogenesis precursors were provided, suggesting the interactions between $C$. cellulovorans and $M$. barkeri might have provided additional metabolic benefits to $M$. barkeri besides supplying the three methanogenesis precursors. The observed physiology of $M$. barkeri in cocultures is reproducible, but whether or not a specific cellulolytic bacterium has to be the coculture partner remains to be determined.

According to the physiological characteristics of the cocultures, a conceptual model that describes the interactions between C. cellulovorans and M. barkeri or $M$. mazei has been developed (Figs. 5a, 6a). In the C. cellulovorans $-M$. barkeri cocultures, cellulose is first fermented to $\mathrm{H}_{2}$, formate, acetate, butyrate, and lactate by C. cellulovorans (Fig. 5a). M. barkeri then consumes the acetate, $\mathrm{H}_{2}$, and formate for cell growth and methanogenesis through both the acetoclastic (Eq. 1) and the $\mathrm{CO}_{2}$ reduction pathways with electrons derived from $\mathrm{H}_{2}$ and formate (Eqs. 2 and 3). The dependence of $M$. barkeri on the metabolites of $C$. cellulovorans is supported by the $\mathrm{H}_{2}$, VFAs, and $\mathrm{pH}$ data, which showed no $\mathrm{H}_{2}$ accumulation, transient accumulation of formate and acetate, and a more stabilized $\mathrm{pH}$ in the cocultures compared to monocultures of $C$. cellulovorans. Consistent with these physiological observations, the $\mathrm{CO}_{2}$ reduction pathway of $M$. barkeri was upregulated (Fig. $5 \mathrm{~b}$ ), supporting that $\mathrm{H}_{2}$ and $\mathrm{CO}_{2}$ were utilized for $\mathrm{CH}_{4}$ production in the $C$. cellulovorans $-M$. barkeri cocultures. Upregulation of the genes encoding the FDH further confirmed that formate was also used as an electron donor for methanogenesis through the $\mathrm{CO}_{2}$ reduction pathway. Unexpectedly, the acetoclastic pathway of $M$. barkeri was upregulated, suggesting that the $\mathrm{CH}_{4}$ production from acetate in the cocultures was more active than in the $M$. barkeri monocultures grown on acetate. Furthermore, upregulation of the genes encoding the MCR suggests that overall $\mathrm{CH}_{4}$ formation was enhanced in the C. cellulovorans $-M$. barkeri cocultures relative to the $M$. barkeri monocultures.

$$
\begin{aligned}
& \mathrm{CH}_{3} \mathrm{COOH} \rightarrow \mathrm{CH}_{4}+\mathrm{CO}_{2} \\
& 4 \mathrm{H}_{2}+\mathrm{CO}_{2} \rightarrow \mathrm{CH}_{4}+2 \mathrm{H}_{2} \mathrm{O} \\
& 4 \mathrm{HCOOH} \rightarrow \mathrm{CH}_{4}+2 \mathrm{H}_{2} \mathrm{O}+3 \mathrm{CO}_{2}
\end{aligned}
$$

In the C. cellulovorans-M. mazei cocultures (Fig. 6a), the interactions between $C$. cellulovorans and $M$. mazei are similar to those in the C. cellulovorans-M. barkeri cocultures, except that formate cannot be utilized by $M$. mazei for methanogenesis because the genes encoding FDH are absent in its genome [21, 22]. Previous studies $[40,41]$ have demonstrated that $M$. mazei can utilize $\mathrm{H}_{2}$ and acetate for methanogenesis. Our results showed no $\mathrm{H}_{2}$ was accumulated throughout the cultivation period in the C. cellulovorans $-M$. mazei cocultures, indicating that the $\mathrm{H}_{2}$ produced by C. cellulovorans was completely utilized for methanogenesis. The upregulation of the genes encoding formylmethanofuran dehydrogenase subunit $\mathrm{F}$ and $\mathrm{G}$ within the $\mathrm{CO}_{2}$ reduction pathway further confirmed that $\mathrm{H}_{2}$ was utilized for methanogenesis (Fig. 6b). For the acetoclastic pathway, as opposed to the depletion of acetate observed in the C. cellulovorans-M. barkeri cocultures, acetate accumulated to a higher concentration in the C. cellulovorans-M. mazei cocultures than in the $C$. cellulovorans monocultures. Moreover, the acetoclastic pathway of M. mazei was downregulated, suggesting that $\mathrm{CH}_{4}$ production from acetate in the cocultures is less active compared to the M. mazei monocultures grown on acetate. However, upregulation of the genes encoding the MCR of M. mazei suggested that overall 
$\mathrm{CH}_{4}$ formation is elevated in the C. cellulovorans $-M$. mazei cocultures.

\section{Stabilization of $\mathrm{pH}$ by methanogens enhanced cellulose degradation}

Due to the consumption of formate and acetate by $M$. barkeri and the reduction in lactate and butyrate production by $C$. cellulovorans, a more stabilized $\mathrm{pH}$ was observed in the C. cellulovorans-M. barkeri cocultures than in the C. cellulovorans monocultures. Studies [35] have shown that acidic $\mathrm{pH}$ can inhibit both the $\mathrm{H}_{2}$ production and the metabolic activity of dark fermenters. Therefore, the more stabilized $\mathrm{pH}$ could potentially improve the cellular metabolism of C. cellulovorans in the cocultures. Accordingly, our results showed that both the rate and extent of cellulose degradation were enhanced (Table 1), and the cellulose degradation pathway of C. cellulovorans was upregulated in the C. cellulovorans-M. barkeri cocultures (Fig. 5b). As a result of a lower accumulated concentration of VFAs, the $\mathrm{pH}$ of the C. cellulovorans $-M$. mazei cocultures was also more stabilized than that of the C. cellulovorans monocultures. However, the $\mathrm{pH}$ of the C. cellulovorans-M. mazei cocultures was lower than that of the $C$. cellulovorans-M. barkeri cocultures as formate and acetate both accumulated in the C. cellulovorans-M. mazei cocultures. Cellulose degradation was also enhanced in the C. cellulovorans-M. mazei cocultures compared to the $C$. cellulovorans monocultures, but to a smaller extent compared to the C. cellulovorans-M. barkeri cocultures. Correspondingly, the cellulose degradation pathway of $C$. cellulovorans was also upregulated in the C. cellulovorans-M. mazei cocultures (Fig. 6b). However, the additional cellulose degraded, and the more optimal pH did not lead to a significant increase in C. cellulovorans cell density in either coculture.

\section{Simultaneous utilization of three methanogenesis precursors promoted $\mathrm{CH}_{4}$ yield}

The $\mathrm{CH}_{4}$ yield of the $C$. cellulovorans $-M$. barkeri cocultures $\left(0.87 \pm 0.02 \mathrm{~mol} \mathrm{CH}_{4} / \mathrm{mol}\right.$ glucose equivalent) was substantially higher than that of the $C$. cellulovoransM. mazei cocultures $\left(0.44 \pm 0.04 \mathrm{~mol} \mathrm{CH}_{4} / \mathrm{mol}\right.$ glucose equivalent) and this could be attributed to two causes. First, besides $\mathrm{H}_{2}$ and acetate, additional electrons can be derived from formate for methanogenesis in the $C$. cellulovorans $-M$. barkeri cocultures, whereas only $\mathrm{H}_{2}$ and acetate can be utilized in the C. cellulovorans-M. mazei cocultures. Second, compared to the C. cellulovorans-M. mazei cocultures, the more stabilized $\mathrm{pH}$ of the $C$. cellulovorans $-M$. barkeri cocultures enabled cellulose degradation to be more complete, which resulted in additional $\mathrm{H}_{2}$, formate, and acetate being produced and provided additional substrates for $\mathrm{CH}_{4}$ production.
The simultaneous utilization of $\mathrm{H}_{2}$, formate, and acetate for methanogenesis in the $C$. cellulovorans-M. barkeri cocultures also has advantages over other reported coculture models, in which only $\mathrm{H}_{2}$ and formate can be utilized for $\mathrm{CH}_{4}$ production. For example, Celine et al. [17] incorporated the $\mathrm{H}_{2}$-consuming methanogens from the human colon with the $\mathrm{H}_{2}$-producing fibrolytic strains to produce $\mathrm{CH}_{4}$ from cellulose, obtaining the highest $\mathrm{CH}_{4}$ yield of $0.33 \pm 0.037 \mathrm{~mol} \mathrm{CH}_{4} / \mathrm{mol}$ glucose equivalent. Bauchop et al. [19] employed the rumen $\mathrm{H}_{2}$ - and formate-utilizing methanogens and the rumen anaerobic fungus for methanogenesis from cellulose, achieving the highest $\mathrm{CH}_{4}$ yield of $0.59 \pm 0.009 \mathrm{~mol} \mathrm{CH}_{4} / \mathrm{mol}$ glucose equivalent. Both of these $\mathrm{CH}_{4}$ yields are significantly lower than the yield obtained in the C. cellulovorans $-M$. barkeri cocultures (Table 1 ).

\section{Metabolic shifts in C. cellulovorans in cocultures}

According to the stoichiometric Eqs. 1 through 3, a theoretical maximum $\mathrm{CH}_{4}$ production of $0.9 \mathrm{mmol}$ is expected from the acetoclastic and $\mathrm{CO}_{2}$ reduction pathways based on $0.3 \pm 0.02 \mathrm{mmol}$ of acetate, $1.5 \pm 0.08 \mathrm{mmol}$ of $\mathrm{H}_{2}$, and $0.9 \pm 0.04 \mathrm{mmol}$ of formate produced in the monocultures of $C$. cellulovorans. However, in the C. cellulovorans-M. barkeri cocultures, a final $\mathrm{CH}_{4}$ amount of $1.5 \pm 0.07 \mathrm{mmol}$ was measured, which exceeds the theoretical maximum production by $66 \%$ according to the $C$. cellulovorans monocultures. This suggests that the sum of $\mathrm{H}_{2}$, formate, and acetate produced by $C$. cellulovorans in the C. cellulovorans $-M$. barkeri cocultures exceeds that of the $C$. cellulovorans monocultures.

Because the concentrations of $\mathrm{H}_{2}$, formate, and acetate measured in the cocultures were determined by both the production rate of $C$. cellulovorans and the consumption rate of $M$. barkeri, it is difficult to accurately calculate the concentration of each metabolite produced. In fact, no $\mathrm{H}_{2}$ accumulation was measured in the cocultures. Alternatively, the gene expressions of the $\mathrm{H}_{2}$, formate, and acetate production pathways were examined. Upregulation of the PFOR and Hyd in the cocultures (Fig. 5b) supports that $\mathrm{H}_{2}$ production of $C$. cellulovorans in the $C$. cellulovorans-M. barkeri cocultures was more active relative to the $C$. cellulovorans monocultures. Concomitant with the enhanced $\mathrm{H}_{2}$ formation, acetate production and the associated adenosine triphosphate (ATP) synthesis for $C$. cellulovorans might also be elevated as additional acetyl-CoA is generated from the enhanced oxidative decarboxylation of pyruvate. Correspondingly, upregulation of the pyruvate to acetate pathway in the cocultures was observed (Fig. 5b). In contrast, downregulation of the pyruvate to formate pathway suggests that the level of formate production was lower in the cocultures 
(Fig. 5b). On the other hand, the final concentrations of lactate and butyrate in the C. cellulovorans-M. barkeri cocultures were lower than in the C. cellulovorans monocultures. Correspondingly, the pathways of pyruvate to lactate and butyrate were both downregulated. Based on the gene expression, the increase in $\mathrm{H}_{2}$ and acetate production together with the decrease in formate, lactate, and butyrate production show that the fermentation pattern of $C$. cellulovorans in the C. cellulovorans-M. barkeri cocultures shifted relative to the $C$. cellulovorans monocultures.

In the $C$. cellulovorans $-M$. mazei cocultures, because acetate accumulated, it is difficult to judge whether acetate was actually consumed for methanogenesis. However, the final produced $\mathrm{CH}_{4}$ was $0.7 \pm 0.09 \mathrm{mmol}$ in the $C$. cellulovorans $-M$. mazei cocultures, which is $0.05 \mathrm{mmol}$ more than the theoretical maximum $\mathrm{CH}_{4}$ yield expected from the sum of $\mathrm{H}_{2}(1.5 \pm 0.08 \mathrm{mmol})$ and acetate $(0.3 \pm 0.02 \mathrm{mmol})$ produced by C. cellulovorans in the monocultures. This suggests that the sum of $\mathrm{H}_{2}$ and acetate consumed by $M$. mazei in the cocultures is more than that produced by $C$. cellulovorans in the monocultures. If acetate was not consumed and excluded for the methanogenesis, the measured $0.7 \pm 0.09 \mathrm{mmol}$ of $\mathrm{CH}_{4}$ production in the C. cellulovorans $-M$. mazei cocultures would require at least $2.9 \mathrm{mmol}$ of $\mathrm{H}_{2}$ (93\% higher than the $\mathrm{H}_{2}$ produced in the C. cellulovorans monocultures) from C. cellulovorans based on the stoichiometric Eq. 2. Instead of such a dramatic increase in $\mathrm{H}_{2}$ production in cocultures, it is more reasonable to postulate that acetate was consumed and also contributed to the total $\mathrm{CH}_{4}$ production in the C. cellulovorans-M. mazei cocultures. If this is the case, the actual acetate produced by C. cellulovorans in the cocultures was significantly more than that produced in the monocultures because there was still $0.4 \pm 0.02 \mathrm{mmol}$ of acetate left in the cocultures. The expected higher $\mathrm{H}_{2}$ and acetate production based on the stoichiometric calculation is supported by the upregulation of the $\mathrm{H}_{2}$ and acetate production pathways of $C$. cellulovorans in the C. cellulovorans $-M$. mazei cocultures. The final concentrations of lactate and butyrate in the C. cellulovorans-M. mazei cocultures were lower than in the C. cellulovorans monocultures, and the pathways of pyruvate to lactate and butyrate correspondingly were both downregulated (Fig. 6b). However, inconsistent with the upregulation of the pyruvate to formate pathway, the final concentration of formate in the C. cellulovorans-M. mazei cocultures was lower than that of the $C$. cellulovorans monocultures (Fig. 6b). Overall, these results suggest that the interactions between $C$. cellulovorans and $M$. mazei also induced a metabolic shift in the fermentation pattern of C. cellulovorans.

\section{Conclusions}

In this study, we report a physiological and molecular investigation of two artificially constructed cocultures utilizing cellulose as the sole carbon substrate. In the cocultures of C. cellulovorans $-M$. barkeri, whereas $C$. cellulovorans produced $\mathrm{H}_{2}$, formate, acetate, butyrate, and lactate as the obligatory fermentation products from cellulose degradation, $M$. barkeri was able to further utilize $\mathrm{H}_{2}$, formate, and acetate for methanogenesis by both the $\mathrm{CO}_{2}$ reduction and acetoclastic pathways. Similar interactions were also observed in the C. cellulovorans-M. mazei cocultures, except that formate cannot be utilized by $M$. mazei for $\mathrm{CH}_{4}$ production. A shift in the fermentation pattern in C. cellulovorans was observed in both cocultures and the more stabilized $\mathrm{pH}$ promoted cellulose degradation and $\mathrm{CH}_{4}$ production. This study illustrates that the use of a constructed coculture to convert cellulosic biomass to $\mathrm{CH}_{4}$ is a viable strategy to produce renewable energy, and the interactions between the microbial partners could lead to beneficial outcomes. Understanding the microbial interactions in such an artificial coculture could provide fundamental guidance in engineering synthetic consortia for a more efficient large-scale biomethanation process.

\section{Additional file}

Additional file 1:Table S1. Primer sequences for selected genes in RTqPCR. Table S2. Primer sequences for internal control genes in RT-qPCR. Figure S1. Acetate concentration and $\mathrm{CH}_{4}$ production profiles of (a) monocultures of M. barkeri and (b) monocultures of M. mazei. Figure S2. (a) Acetate and formate concentrations and (b) $\mathrm{H}_{2}$ consumption and $\mathrm{CH}_{4}$ production of monocultures of $M$. barkeri grown with $10 \mathrm{mM}$ of formate, 3 $\mathrm{mM}$ of acetate, and $0.95 \mathrm{mmol}$ of $\mathrm{H}_{2}$. Figure $\mathbf{S 3}$. (a) Acetate concentration and (b) $\mathrm{H}_{2}$ consumption and $\mathrm{CH}_{4}$ production of monocultures of $M$. barkeri grown with $3 \mathrm{mM}$ of acetate and $0.95 \mathrm{mmol}$ of $\mathrm{H}_{2}$. Table S3. Products of cellulose fermentation by C. cellulovorans monocultures. Table S4. Gene expression of the selected C. cellulovorans (CC) genes in response to cocultivation with $M$. barkeri $(M B)$ or $M$. mazei $(M M)$ at mid-exponential growth phase. Table S5. Gene expression of the selected M. barkeri (MB) genes in response to cocultivation with C. cellulovorans (CC) at midexponential growth phase. Table S6. Gene expression of the selected $M$. mazei (MM) genes in response to cocultivation with C. cellulovorans (CC) at mid-exponential growth phase Figure S4. Comparison of the increase in cell density over the course of the experiment. Cell density at time zero was about $3.0 \times 10^{7}$ cells $/ \mathrm{mL}$ for the experiments.

\footnotetext{
Abbreviations

$\mathrm{CH}_{4}$ : methane: $\mathrm{H}_{2}$ : hydrogen; $\mathrm{CO}_{2}$ : carbon dioxide; $\mathrm{NADH}$ : nicotinamide adenine dinucleotide; $\mathrm{NAD}^{+}$: oxidized form of nicotinamide adenine dinucleotide; SEM: scanning electron microscopy; qPCR: quantitative PCR; RIN: RNA integrity number; RT: reverse transcription; CDNA: complementary DNA; Ct: comparative threshold; gap: glyceraldehyde dehydrogenase; VFAs: volatile fatty acids; Hyd: hydrogenase; PFOR: pyruvate:ferredoxin oxidoreductase; acetyl-CoA:
} 
acetyl coenzyme A; acetyl-P: acetyl phosphate; MCR: methyl-coenzyme M reductase; FDH: formate dehydrogenase; ATP: adenosine triphosphate; ADP: adenosine diphosphate; $\mathrm{FADH}_{2}$ : flavin-adenine dinucleotide; $\mathrm{Fd}_{\text {rex }}$ : reduced form of ferredoxin; $\mathrm{Fd}_{\mathrm{ox}}$ : oxidized form of ferredoxin; $\mathrm{HS}-\mathrm{CoA}$ : coenzyme A; Formyl-MFR: a formylmethanofuran; Formyl- ${ }_{4}$ MPT: 5-formyl-tetrahydromethanopterin; Methenyl- ${ }_{4}$ MPT: 5, 10-methenyltetrahydromethanopterin; Methylene- $\mathrm{H}_{4} \mathrm{MPT}$ : 5,10-methylene-tetrahydromethanopterin; Methyl- $\mathrm{H}_{4} \mathrm{MPT}$ : 5-methyl-tetrahydromethanopterin; Methyl- $\mathrm{H}_{4} \mathrm{SPT}$ : 5-methyl-tetrahydrosarcinapterin; $\mathrm{CH}_{3}-\mathrm{Co}(\mathrm{III}) \mathrm{FeSP}$ : a methylated corrinoid Fe-S protein.

\section{Authors' contributions}

HYL designed the study, performed the experiments, analyzed the data, and wrote the manuscript. SKN carried out some of the data analyses. YYJ and MWC performed some of the experiments. PKHL conceived of, designed and supervised, the study, and revised the manuscript. All authors read and approved the final manuscript.

\section{Acknowledgements}

This research was supported by the Research Grants Council of Hong Kong through Project 11206514.

\section{Competing interests}

The authors declare that they have no competing interests.

\section{Availability of data and materials}

All data generated or analyzed during this study are included in this published article [and its supplementary information files].

\section{Funding}

This research was supported by the Research Grants Council of Hong Kong through Project 11206514.

Received: 17 August 2016 Accepted: 27 January 2017

Published online: 07 February 2017

\section{References}

1. Frigon JC, Guiot SR. Biomethane production from starch and lignocellulosic crops: A comparative review. Biofuels Bioprod Biorefin. 2010;4:447-58.

2. Ferry JG. Acetate-based methane production. In: Wall JD, Harwood CS, Demain A, editors. Bioenergy. Washington, DC: ASM Press; 2008. p 155-70.

3. Rittmann BE. Opportunities for renewable bioenergy using microorganisms. Biotechnol Bioeng. 2008;100:203-12.

4. Caspeta L, Buijs NAA, Nielsen J. The role of biofuels in the future energy supply. Energy Environ Sci. 2013;6:1077-82

5. Hattori S. Syntrophic acetate-oxidizing microbes in methanogenic environments. Microbes Environ. 2008;23:118-27.

6. Thauer RK, Kaster AK, Seedorf H, Buckel W, Hedderich R. Methanogenic archaea: ecologically relevant differences in energy conservation. Nat Rev Microbiol. 2008;6:579-91.

7. Garcia JL, Patel BKC, Ollivier B. Taxonomic, phylogenetic, and ecological diversity of methanogenic Archaea. Anaerobe. 2000;6:205-26.

8. Deppenmeier U, Müller V, Gottschalk G. Pathways of energy conservation in methanogenic archaea. Arch Microbiol. 1996;165:149-63.

9. Stams AJM, Plugge CM. Electron transfer in syntrophic communities of anaerobic bacteria and archaea. Nat Rev Microbiol. 2009:7:568-77.

10. Bryant MP, Campbell LL, Reddy CA, Crabill MR. Growth of Desulfovibrio in lactate or ethanol media Low in sulfate in association with $\mathrm{H}_{2}$-utilizing methanogenic bacteria. Appl Environ Microbiol. 1977;33:1162-9.

11. Mclnerney MJ, Bryant MP. Anaerobic degradation of lactate by syntrophic associations of Methanosarcina barkeri and Desulfovibrio species and effect of $\mathrm{H}_{2}$ on acetate degradation. Appl Environ Microbiol. 1981;41:346-54

12. Burrell PC, O'Sullivan C, Song H, Clarke WP, Blackall LL. Identification, detection, and spatial resolution of Clostridium populations responsible for cellulose degradation in a methanogenic landfill leachate bioreactor. Appl Environ Microbiol. 2004;70:2414-9.
13. Shiratori H, Ikeno H, Ayame S, Kataoka N, Miya A, Hosono K, Beppu T, Ueda K. Isolation and characterization of a new Clostridium sp. that performs effective cellulosic waste digestion in a thermophilic methanogenic bioreactor. Appl Environ Microbiol. 2006;72:3702-9.

14. Zinder SH. Physiological ecology of methanogens. In: Ferry JG, editor. Methanogenesis: ecology, physiology, biochemistry and genetics. Boston: Springer; 1993. p. 128-206.

15. Laube VM, Martin SM. Conversion of cellulose to methane and carbon dioxide by triculture of Acetivibrio cellulolyticus, Desulfovibrio sp., and Methanosarcina barkeri. Appl Environ Microbiol. 1981;42:413-20.

16. Nakashimada Y, Srinivasan K, Murakami M, Nishio N. Direct conversion of cellulose to methane by anaerobic fungus Neocallimastix frontalis and defined methanogens. Biotechnol Lett. 2000;22:223-7.

17. Robert C, Del'Homme C, Bernalier-Donadille A. Interspecies $\mathrm{H}_{2}$ transfer in cellulose degradation between fibrolytic bacteria and $\mathrm{H}_{2}$-utilizing microorganisms from the human colon. FEMS Microbiol Lett. 2001;205:209-14

18. Sasaki D, Morita M, Sasaki K, Watanabe A, Ohmura N. Acceleration of cellulose degradation and shift of product via methanogenic co-culture of a cellulolytic bacterium with a hydrogenotrophic methanogen. J Biosci Bioeng. 2012;114:435-9.

19. Bauchop T, Mountfort DO. Cellulose fermentation by a rumen anaerobic fungus in both the absence and the presence of rumen methanogens. Appl Environ Microbiol. 1981;42:1103-10.

20. Tamaru Y, Miyake H, Kuroda K, Nakanishi A, Kawade Y, Yamamoto K, Uemura M, Fujita Y, Doi RH, Ueda M. Genome sequence of the cellulosome-producing mesophilic organism Clostridium cellulovorans 743B. J Bacteriol. 2010;192:901-2.

21. Maeder DL, Anderson I, Brettin TS, Bruce DC, Gilna P, Han CS, Lapidus A, MetcalfWW, Saunders E, Tapia R, Sowers KR. The Methanosarcina barker genome: comparative analysis with Methanosarcina acetivorans and Methanosarcina mazei reveals extensive rearrangement within Methanosarcinal genomes. J Bacteriol. 2006:188:7922-31.

22. Assis das Graças D, Thiago Jucá Ramos R, Vieira Araújo AC, Zahlouth R, Ribeiro Carneiro A, Souza Lopes T, Azevedo Baraúna R, Azevedo V, Cruz Schneider MP, Pellizari VH, Silva A. Complete genome of a Methanosarcina mazei strain isolated from sediment samples from an amazonian flooded area. Genome Announc. 2013;1:270-283.

23. He J, Holmes VF, Lee PKH, Alvarez-Cohen L. Influence of vitamin $B_{12}$ and cocultures on the growth of Dehalococcoides isolates in defined medium. Appl Environ Microbiol. 2007;73:2847-53.

24. Goevert D, Conrad R. Effect of substrate concentration on carbon isotope fractionation during acetoclastic methanogenesis by Methanosarcina barkeri and M. acetivorans and in rice field soil. Appl Environ Microbiol. 2009;75:2605-12

25. Sleat R, Mah RA, Robinson R. Isolation and characterization of an anaerobic, cellulolytic bacterium, Clostridium cellulovorans sp. nov. Appl Environ Microbiol. 1984;48:88-93.

26. Sander R. Compilation of Henry's law constants (version 4.0) for water as solvent. Atmos Chem Phys. 2015;15:4399-981.

27. Lu H, Lee PKH. Effects of cellulose concentrations on the syntrophic interactions between Clostridium cellulovorans $743 \mathrm{~B}$ and Rhodopseudomonas palustris CGA009 in coculture fermentation for biohydrogen production. Int J Hydrog Energy. 2015;40:11800-8.

28. DuBois M, Gilles KA, Hamilton JK, Rebers PA, Smith F. Colorimetric method for determination of sugars and related substances. Anal Chem. 1956:28:350-6.

29. Cheung HY, Wong MMK, Cheung SH, Liang LY, Lam YW, Chiu SK. Differential actions of chlorhexidine on the cell wall of Bacillus subtilis and Escherichia coli. PLoS ONE. 2012;7:e36659.

30. Lu H, Chen J, Jia Y, Cai M, Lee PKH. Transcriptomic responses of the interactions between Clostridium cellulovorans $743 \mathrm{~B}$ and Rhodopseudomonas palustris CGA009 in a cellulose-grown coculture for enhanced hydrogen production. Appl Environ Microbiol. 2016:82:4546-59.

31. Livak KJ, Schmittgen TD. Analysis of relative gene expression data using real-time quantitative PCR and the $2^{-\triangle \Delta C T}$ method. Methods. 2001;25:402-8

32. Suzuki T, Higgins PJ, Crawford DR. Control selection for RNA quantitation. BioTechniques. 2000;29:332-7.

33. VanGuilder HD, Vrana KE, Freeman WM. Twenty-five years of quantitative PCR for gene expression analysis. BioTechniques. 2008;44:619-26. 
34. Krätzer C, Carini P, Hovey R, Deppenmeier U. Transcriptional profiling of methyltransferase genes during growth of Methanosarcina mazei on trimethylamine. J Bacteriol. 2009;191:5108-15.

35. Liu IC, Whang L-M, Ren W-J, Lin P-Y. The effect of $\mathrm{pH}$ on the production of biohydrogen by clostridia: Thermodynamic and metabolic considerations. Int J Hydrog Energy. 2011;36:439-49.

36. Tamaru Y, Miyake H, Kuroda K, Nakanishi A, Matsushima C, Doi RH, Ueda M. Comparison of the mesophilic cellulosome-producing Clostridium cellulovorans genome with other cellulosome-related clostridial genomes. Microb Biotechnol. 2010;4:64-73.

37. Deppenmeier U, Johann A, Hartsch T, MerkI R, Schmitz RA, Martinez-Arias R, Henne A, Wiezer A, Baumer S, Jacobi C, et al. The genome of Methanosarcina mazei: evidence for lateral gene transfer between bacteria and archaea. J Mol Microbiol Biotechnol. 2002:4:453-61.
38. Jäger D, Sharma CM, Thomsen J, Ehlers C, Vogel J, Schmitz RA. Deep sequencing analysis of the Methanosarcina mazei Gö1 transcriptome in response to nitrogen availability. Proc Natl Acad Sci USA. 2009;106:21878-82.

39. Londry KL, Dawson KG, Grover HD, Summons RE, Bradley AS. Stable carbon isotope fractionation between substrates and products of Methanosarcina barkeri. Org Geochem. 2008;39:608-21.

40. Ferguson TJ, Mah RA. Effect of $\mathrm{H}_{2}-\mathrm{CO}_{2}$ on methanogenesis from acetate or methanol in Methanosarcina spp. Appl Environ Microbiol. 1983;46:348-55.

41. Maestrojuán GM, Boone DR. Characterization of Methanosarcina barkeri MST and 227, Methanosarcina mazei S-6T, and Methanosarcina vacuolata Z-761T. Int J Syst Evol Microbiol. 1991;41:267-74.

\section{Submit your next manuscript to BioMed Central and we will help you at every step:}

- We accept pre-submission inquiries

- Our selector tool helps you to find the most relevant journal

- We provide round the clock customer support

- Convenient online submission

- Thorough peer review

- Inclusion in PubMed and all major indexing services

- Maximum visibility for your research

Submit your manuscript at www.biomedcentral.com/submit 